\title{
Comparing test systems to measure the salinity tolerance of freshwater invertebrates
}

\author{
Ben J Kefford ${ }^{1 *}$, Carolyn G Palmer ${ }^{2}$, Larisa Pakhomova ${ }^{2, \#}$ and Dayanthi Nugegoda ${ }^{1}$ \\ ${ }^{1}$ Biotechnology and Environmental Biology, School of Applied Sciences, RMIT University, Bundoora, 3083, Victoria, Australia \\ 2 Unilever Centre for Environmental Water Quality, Institute for Water Research, Rhodes University, Grahamstown, 6139, \\ Eastern Cape, South Africa
}

\begin{abstract}
There have recently been several studies into acute salinity tolerance of freshwater invertebrates using different methods, making comparisons between studies difficult. The alternatives focus on experimental flow regimes and ionic proportions. In this study non-rheophilic riverine taxa collected in South Africa and south-east Australia were variously exposed to solutions of sodium chloride $(\mathrm{NaCl})$ and the artificial sea salt, Ocean Nature, in flowing and still water. South African species: Euthraulus elegans (Ephemeroptera: Leptophlebiidae), Micronecta piccanina (Hemiptera: Corixidae), Burnupia stenochorias (Gastropoda: Ancylidae) and Caridina nilotica (Decapoda: Atyidae); Australian collected species: Daphnia carinata (Cladocera: Daphniidae), Micronecta annae and Physa acuta (Gastropoda: Physidae). The main findings were:

- The salinity tolerances of a range of taxa were not affected by flow regimes

- Taxa were less sensitive to the artificial sea salt than $\mathrm{NaCl}$

- There was, however, a direct relationship between the $\mathrm{LC}_{50}$ values from both salts. This relationship was used to compare the $\mathrm{LC}_{50}$ values from studies testing (artificial or natural) sea-water or $\mathrm{NaCl}$.

- The comparison indicated variation in the mean $\mathrm{LC}_{50}$ between studies that is probably, at least in part, due to the range of taxonomic groups and rarities of species tested.

When comparing the acute salinity tolerance of non-rheophilic invertebrates, the salt source and criteria for choosing species affect the results, but the flow environment probably does not.
\end{abstract}

Keywords: stream invertebrates, acute salinity tolerance, test system

\section{Introduction}

Salinity in rivers and wetlands is increasing in many arid and semiarid regions of the world including Southern Africa and Australia (Williams, 1987). There is considerable uncertainty about the effect of this increase on aquatic biota and detailed investigations of salinity tolerance are needed (Hart et al., 1991; Clunie et al., 2002). A number of studies have used a variety of different methods to investigate the acute salinity tolerance of macroinvertebrates making comparisons difficult.

A variety of different salt sources and experimental systems have been used in laboratory salinity tolerance experiments. In both Australia (Kefford et al., 2003; 2004) and South Africa (Kefford, 2002) non-flowing water has been used as a simplified and standardised system for rapidly testing many species. Other studies in South Africa, Palmer et al. (1996), Goetsch and Palmer (1997), Palmer and Rossouw (2000) and Palmer and Scherman (2000), have used a flowing environment to mimic a natural stream. Kefford et al. (2003, 2004) used artificial sea-water because in Australia most inland waters have ionic proportions similar to sea-water (Bayly and Williams, 1973: 1; Williams and Buckney, 1976a; b; Herczeg et al., 2001). Palmer and co-workers used sodium chloride ( $\mathrm{NaCl}$ ) and sodium sulphate $\left(\mathrm{Na}_{2} \mathrm{SO}_{4}\right)$ because most agriculture-induced

\# Current address, Department of Earth and Ocean Sciences, University of British Columbia, 2219 Main Mall, Vancouver, V6T 1Z4, Canada

* To whom all correspondence should be addressed.

巡+6139925 7110; fax:+ 6139925 7126;

e-mail: ben.kefford@rmit.edu.au

Received 16 January 2004; accepted in revised form 18 June 2004. salinisation in South Africa is $\mathrm{NaCl}$ dominated and most saline industrial and mine effluents are $\mathrm{SO}_{4}^{2-}$ dominated (Dallas and Day, 1993). Other studies have also used $\mathrm{NaCl}$ (Clemens and Jones, 1954; Williams et al., 1999; Blasius and Merritt, 2002) or sea-water (Shirgur and Kewalramani, 1977; Mills and Geddes, 1980; Williams, 1984; Williams and Williams 1998) to investigate the salt tolerance of freshwater macroinvertebrates. Although $\mathrm{Na}^{+}$and $\mathrm{Cl}^{-}$are the most common ions in sea-water, the presence of other ions may result in differences in the tolerance of macroinvertebrates to $\mathrm{NaCl}$ and (natural or artificial) sea-water. For example, Daphnia magna $48 \mathrm{~h} \mathrm{LC}_{50}$ values for various salts ranged from 0.63 to $7.98 \mathrm{~g} / \ell$ for various salts (Mount et al., 1997). Direct comparisons between studies using different salts are therefore difficult.

There are also differences in the criteria for choosing species to investigate. Palmer and co-workers chose one to six species per publication, sometimes considering the same species collected from different locations in different publications, and only included species collectable in high numbers. They mostly tested Ephemeroptera but tested fewer species of Trichoptera and Gastropoda. Ephemeroptera, especially Baetidae, are salt-sensitive compared with other macroinvertebrates (Clemens and Jones, 1954; Hart et al., 1991; Short et al., 1991; Williams and Williams, 1998; Kefford et al., 2003). The tolerances of species from this order are therefore unlikely to reflect the salinity tolerance of most members of natural communities (see Forbes and Calow, 2002). Kefford (2002) and Kefford et al. (2003) attempted to select species from orders in approximate proportion to which the orders were found in the locality where they were collecting macroinvertebrates. This resulted in a relatively large number of taxa ( 49 and 57 , respectively) from many higher taxonomic groups ( 9 and 16 orders, respectively), 
including taxa found at low abundances. Other studies have given a range of explanations for how species were selected. In Canada, Williams et al. (1999) chose six abundant species for testing, four of which were generally associated with low salinity sites while the remaining two species were associated with high salinity sites. In the USA, Blasius and Merritt (2002) chose six species from five orders to represent a number of different trophic levels, habitat requirements, respiration systems and taxonomic groups.

Directly comparing the salinity tolerance of species tested using different methods will not indicate whether any differences observed are due to real differences in tolerances or simply a reflection of the method used. Even if different methods of testing do not affect salinity tolerance, the criteria for selecting species may result in different studies showing differences in the range of tolerances where none exist. It is therefore not always possible to ascertain whether two locations tend to have species that are more or less tolerant, making it difficult to test hypotheses (Nielsen and Hillman, 2000; Kay et al., 2001) about spatial variation in salinity tolerance. In this paper we compare several methods of testing the salinity tolerance of macroinvertebrate species:

- The effect of flow (flowing water vs. standing water)

- The effect of salt source ( $\mathrm{NaCl}$ vs. the artificial sea salt, Ocean Nature [Aquasonic, Wauchope, New South Wales, Australia]). We hypothesise that if flow or salt source affects salinity tolerance then $\mathrm{LC}_{50}$ values should differ between flow systems/ salt sources.

- The effect of test species selection, which we explore by comparing the mean and the range of $\mathrm{LC}_{50}$ values from selected studies.

As a secondary aim we compare the $\mathrm{LC}_{50}$ values obtained from $72 \mathrm{~h}$ and $96 \mathrm{~h}$ tests.

\section{Methods}

\section{General methods}

Macroinvertebrates were collected in the field and brought back to the laboratory in the water that they were collected in and the experiments were started once that water was approximately the ambient airtemperature of the laboratory $\left(20^{\circ} \mathrm{C}\right)$. No other acclimation was conducted. The control and diluting water used in the experiments was Melbourne or Grahamstown tap-water, for the Australian and South African experiments respectively, that had been carbon-filtered and in the case of the Australian experiments also sand-filtered.

Animals were regarded as dead if they were not moving and failed to respond to probing. Snails that had retracted into their shell were placed in freshwater for $30 \mathrm{~min}$ and if they failed to respond were regarded as dead. Dead individuals were removed when survivorship had been checked.

Except where noted, salinity in this paper is measured in terms of electrical conductivity or EC (mS/cm; note $1 \mathrm{mS} / \mathrm{cm}=1000 \mathrm{uS} /$ $\mathrm{cm}=100 \mathrm{mS} / \mathrm{m}$ ) adjusted to $25^{\circ} \mathrm{C}$, as it is the most common measure of salinity and is also rapidly, accurately and reliably measurable. Experiments were conducted over a variety of periods. The experiment with Daphnia carinata was conducted over $48 \mathrm{~h}$ as $24 \mathrm{~h}$ or 48 $\mathrm{h}$ as is standard with this genus (Walker et al., 1996: 127). Experiments with most other species were conducted over $96 \mathrm{~h}$ but results are also reported at $72 \mathrm{~h}$ to ensure comparability with studies reporting over this period. Experience has shown that some Micronecta have high mortality between 72 and $96 \mathrm{~h}$ and the experiments with Micronecta annae were performed over $72 \mathrm{~h}$. As is standard, animals were not fed during acute experiments (OECD, 1996; ASTM, 1998).

Standard logistic regression (Agresti, 1990) was used, with the dependent variable the probability of survival and the independent variable the EC. The concentrations lethal to $50 \%$ of individuals $\left(\mathrm{LC}_{50}\right.$ ) and their $95 \%$ confidence intervals (CI) were calculated from this regression giving an alpha level of 0.05 .

\section{The effect of flow}

The effect of the two different flow-environments: flowing channels and non-flowing aquaria on the salinity tolerances of four South African species were determined concurrently in August 2002. Euthraulus elegans (Ephemeroptera: Leptophlebiidae) and Micronecta piccanina (Hemiptera: Corixidae) were collected from the Kat River at Amherst (S $32{ }^{\circ} 38^{\prime}$; E $26^{\circ}$ 41'). Burnupia stenochorias (Gastropoda: Ancylidae) were collected from the Botha River at Visgat Pool (S 33 13'; E 26 30'). See Kefford 2002 and Kefford et al. (2004) for site information. M. piccanina were caught with a sweep net from slow-flowing pools, E. elegans were picked off cobbles in a riffle with a fine brush and $B$. stenochorias were carefully removed from stones from a large pool. Caridina nilotica (Decapoda: Atyidae) were obtained from a laboratory colony that was originally stocked from Mpisini Stream in Richards Bay, KwaZulu-Natal (see Kefford et al., 2004). No species was rheophilic (living only in fastflowing water). E. elegans and B. stenochorias are regularly found in both fast-flowing riffles and slower-flowing sections of streams, while the other two are predominately found in slower-flowing parts and within fringe vegetation (Personal observations). The four species were chosen because they could be obtained in numbers sufficient to perform the experiment ( $>160$ individuals) and represented a range of taxonomic groups, modes of locomotion and assumed salinity tolerances.

The flowing channels were small-scale artificial streams consisting of $1 \mathrm{~m}$ of plastic gutters (or channels) that overflow at their downstream end into a bucket where a submersible pump in each bucket returned water to the upstream end of its channel (DWAF, 2000). Mesh prevented animals from flowing into the bucket. A strip of mesh and four small stones were placed on the channel bottom to provide the animals with a rough surface for attachment and a range of flow environments, respectively.

Ten salinity treatments were prepared (control, 5.5, 9.6, 16, 18, 21, 23, 30, 35 and $41 \mathrm{mS} / \mathrm{cm}$ ) by dissolving Ocean Nature salt. For each treatment there was one channel with $20 \ell$ of water and three glass aquarium tanks with $6.6 \ell$ of water and a third as many animals as the channel, so that densities (animals/ $\ell$ ) were equal in both systems. Water was aerated in the aquariums and both systems had high dissolved oxygen (> 80\% saturation).

Due to a limited number of animals available and differences in their assumed salinity tolerances, not all species were subject to all salinity treatments. C. nilotica were subject to all, while B. stenochorias to all $\leq 35 \mathrm{mS} / \mathrm{cm}$ and E. elegans and M. piccaninain to all $\leq 30 \mathrm{mS} / \mathrm{cm}$. Differing numbers of individuals were available for each species: the numbers exposed in each channel and aquarium were 24 and 8, respectively, for C. nilotica and E. elegans, 7 and 21 for M. piccaninain and 6 and 18 for B. stenochorias. Individuals emerging as flying adults or otherwise not locatable were excluded from the analysis.

In the tanks different species were prevented from physically interacting by housing them separately in containers that allowed for circulation of water. Due to its larger size, C. nilotica was housed unconstrained in the aquaria while the other three species were 
housed in separate containers. The channels were divided into two, by means of a mesh barrier, and E. elegans and B. stenochorias were housed in the upstream section and the other species in the downstream section.

\section{The effect of salts}

The tolerances to Ocean Nature salt and $\mathrm{NaCl}$ were determined using three species collected from Australia (Daphnia carinata [Cladocera: Daphniidae], Micronecta annae and the introduced snail Physa acuta [Gastropoda: Physidae]) and two South African species (C. nilotica and E. elegans). The tolerance of C. nilotica to $\mathrm{Na}_{2} \mathrm{SO}_{4}$ was also determined. These species were chosen because they could be obtained in sufficient numbers, represented several higher taxonomic groups and assumed salinity tolerance.

As part of a study into the toxicity of various saline lakes to Daphnia carinata (Kefford, 2000a; Kefford et al., 2002) the $48 \mathrm{~h}$ lethal tolerance to Ocean Nature and analytical grade $\mathrm{NaCl}$ were determined. $D$. carinata were obtained from a laboratory colony originally stocked from the Yarra River (near Melbourne). For further details of the methods see Kefford (2000a).

Micronecta annae and Physa acuta were collected from the Barwon River at Pollocksford Bridge (S $38^{\circ} 09^{\prime}$; E $144^{\circ} 11^{\prime}$ ) in January 2002 and 2003, respectively, and tested for their tolerance to Ocean Nature and $\mathrm{NaCl}$ (Dominion Salt Limited, New Zealand with a minimum $\mathrm{NaCl}$ content of $99.9 \%)$. M. annae was tested in five salinity treatments (control and 6.4, 12.6, 15 and $25.6 \mathrm{mS} / \mathrm{cm}$ ), while seven salinity treatments (control, 5.0, 7.5, 10, 12.5, 15 and $20 \mathrm{mS} / \mathrm{cm}$ ) were used with $P$. acuta. These treatments were selected from past experimentation with these species (Kefford et al., 2003). In each treatment there were three $500 \mathrm{~m} \ell$ containers with approximately $450 \mathrm{~m} \ell$ of water in each and six M. annae or three $P$. acuta.

The tolerance of $C$. nilotica from the aforementioned laboratory colony to Ocean Nature, $\mathrm{NaCl}$ and $\mathrm{Na}_{2} \mathrm{SO}_{4}$ was determined in aquaria over $96 \mathrm{~h}$. There were 10 salinity treatments (control, 1,3 , $5,7,9,11,13,15$ and $18 \mathrm{~g} / \ell$ ) for each salt with an additional three salinity treatments $(20,25$ and $30 \mathrm{~g} / \ell$ ) for Ocean Nature. The EC of the water in each aquarium was measured. Each treatment consisted of one aquarium with $6.6 \ell$ of water and 10 shrimps held unconstrained with no other species.

In October 2002, E. elegans collected from the Kat River at Amherst were tested in aquaria to Ocean Nature and $\mathrm{NaCl}$ over $240 \mathrm{~h}(10 \mathrm{~d})$. There were 10 salinity treatments (control, 0.3, 0.5, $0.8,1.4,2.3,3.9,6.5,10.8$ and $18 \mathrm{~g} / \ell$ ) each comprising a single aerated aquarium with 21 individuals. The EC for both salts in each treatment was measured. E. elegans were not fed nor was the water changed for the first $96 \mathrm{~h}$ of the experiment. At $96 \mathrm{~h}$ the water was changed and E. elegans were fed $0.02 \mathrm{~g}$ of ground Tetramin (fish flakes) per treatment. A second feeding and water change occurred at $192 \mathrm{~h}(8 \mathrm{~d})$.

\section{The effect of species selection}

$\mathrm{LC}_{50}$ values from selected studies were compared to determine the similarity of salinity tolerances. Due to the presence of $\mathrm{LC}_{50}$ values given as $>$ some value, or censored data (Smith, 2002), the mean $L_{50}$ was calculated using the Kaplan-Meier method (see Kefford et al., 2003). Where $\mathrm{LC}_{50}$ were measured in total dissolved salts (TDS) they were converted to EC in terms of Ocean Nature using the formula EC (in mS/cm) = TDS (in g/ $\ell$ ) $/ 0.754$ (Kefford et al., 2003). Where multiple $\mathrm{LC}_{50}$ values were calculated for a species with the same salt (for different collection locations or dates) the arithmetic mean value for each species was used.

\section{Results}

\section{The effect of flow}

Survival in the controls was high (> 90\%) in all species except M. piccanina over 96 h(Figs. 1a-c). For M. piccanina control survival was $81 \%$ at 72 h (Fig. 1d) and $66 \%$ at 96 h. This species had considerable mortality in all treatments between $72 \mathrm{~h}$ and $96 \mathrm{~h}$ making for wide $95 \% \mathrm{CI}$ of $\mathrm{LC}_{50}$ at $96 \mathrm{~h}$ (Table 1). Each species in both systems responded to Ocean Nature salt similarly (Fig. 1) with
Figure 1

Salinity tolerance of four species in the two test systems a) Burnupia stenochorias @ $96 \mathrm{~h}$

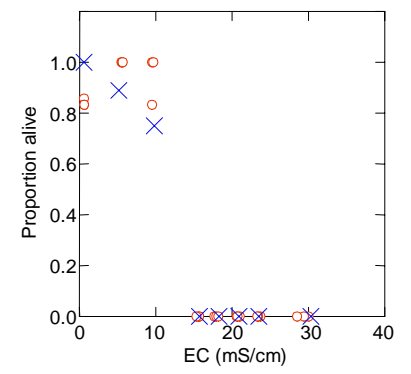

c) Euthraulus elegans @ 96 h

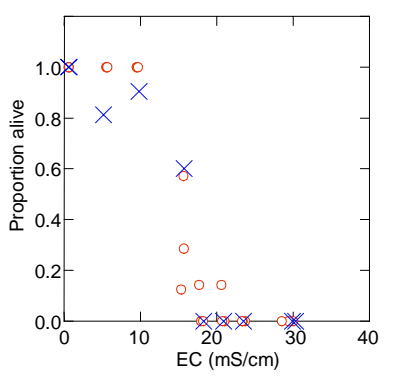

\section{b) Caridina nilotica @ 96 h}

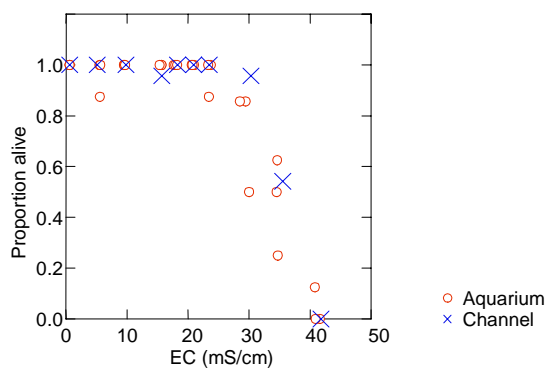

d) Micronecta piccanina @ 72 h

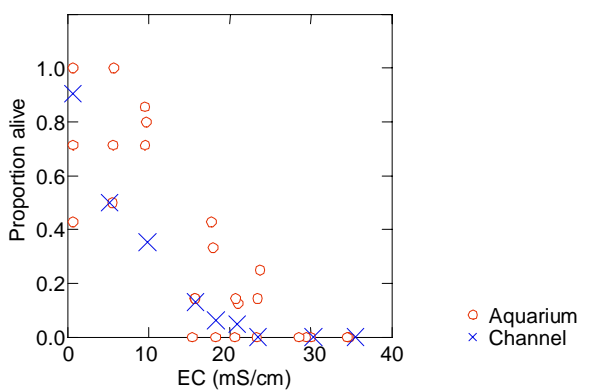


$\mathrm{LC}_{50}$ values having overlapping $95 \%$ CIs, indicating no significant difference between systems (Table 1 ). Indeed the difference in $\mathrm{LC}_{5}$ values between systems ranged from 0 to $2.7 \mathrm{mS} / \mathrm{cm}$, thus even if a Type two error has occurred, the differences between systems are of little practical consequence. Due to the similarity of the LC $_{50}$ values between systems we also report them calculated from all data (combined).

$\mathrm{LC}_{50}$ values for $B$. stenochorias were identical whether calculated over $72 \mathrm{~h}$ or $96 \mathrm{~h}$ of exposure (Table 1 ). The $96 \mathrm{~h} \mathrm{LC}_{50}$ values for E. elegans and C. nilotica were $87 \%$ and $97 \%$, respectively, of their $72 \mathrm{~h} \mathrm{LC}_{50}$ value. For M. piccanina the $96 \mathrm{hLC}_{50}$ value was about half the $72 \mathrm{~h} \mathrm{LC}_{50}$ value; however, as noted above, the high mortality in all treatments between $72 \mathrm{~h}$ and $96 \mathrm{~h}$ suggests that $72 \mathrm{~h}$ of exposure is more appropriate for this species.

\section{The effect of salts}

Survivorship in the controls over the acute exposure periods was high (Table 2, Figs. 2 to 6 ) for all species investigated. In four of the five species the $\mathrm{LC}_{50}$ for Ocean Nature was statistically significantly higher than that for $\mathrm{NaCl}$ in all time periods. The exception, M. annae, had overlapping $95 \%$ CIs but followed the same trend (Table 2, Fig. 3). The $\mathrm{LC}_{50}$ value for C. nilotica exposed to $\mathrm{Na}_{2} \mathrm{SO}_{4}$ was lower still than that for $\mathrm{NaCl}$ (Table 2, Fig. 5).

The $\mathrm{LC}_{50}$ values calculated after both $72 \mathrm{~h}$ and $96 \mathrm{~h}$ of exposure were identical for P. acuta (Table 2). For C. nilotica the $96 \mathrm{~h}$ values were between 85 and $97 \%$ of the $72 \mathrm{~h} \mathrm{LC}_{50}$ values, while for E. elegans the $96 \mathrm{~h}$ values were 92 to $94 \%$ of the $72 \mathrm{~h}$ values.

Tolerance to Ocean Nature salt was well correlated with tolerance to $\mathrm{NaCl}$ (Fig. 7). While the sample size was small $(\mathrm{n}=5)$ there was a statistically significant relationship between the $\mathrm{LC}_{50}$ for $\mathrm{NaCl}$ and the log-transformed $\mathrm{LC}_{50}$ for Ocean Nature $(\mathrm{r}=0.91$, $\mathrm{P}=0.033)$. The best relationship is described by:

$$
\begin{aligned}
\log _{10}\left(\mathrm{LC}_{50} \text { for Ocean Nature }\right)= & 0.83+0.035 \\
& \left(\mathrm{LC}_{50} \text { for } \mathrm{NaCl}\right)
\end{aligned}
$$

\begin{tabular}{|c|c|c|c|}
\hline \multicolumn{4}{|c|}{$\begin{array}{c}\text { TABLE1 } \\
\mathrm{LC}_{50} \text { values in } \mathrm{mS} / \mathrm{cm} \text { (with } 95 \% \mathrm{Cl} \text { ) for four species in two } \\
\text { different test system. Combined is calculated using all data } \\
\text { from both systems }\end{array}$} \\
\hline Species & System & $72 \mathrm{~h}$ & $96 \mathrm{~h}$ \\
\hline \multirow[t]{3}{*}{ Micronecta piccanina } & Aquarium & $10(7.7-13)$ & $4.8(1.5-7.2)$ \\
\hline & Channel & $7.3(4.8-9.4)$ & $3.8(1.4-5.8)$ \\
\hline & Combined & $8.9(7.1-10)$ & $4.3(2.4-5.9)$ \\
\hline \multirow[t]{3}{*}{ Burnupia stenochorias } & Aquarium & $11(9.6-13)$ & $11(9.6-13)$ \\
\hline & Channel & $11(9.3-12)$ & $11(9.3-12)$ \\
\hline & Combined & $11(9.9-12)$ & $11(9.9-12)$ \\
\hline \multirow[t]{3}{*}{ Euthraulus elegans } & Aquarium & $16(15-17)$ & $15(13-16)$ \\
\hline & Channel & $15(14-17)$ & $14(12-15)$ \\
\hline & Combined & $16(15-17)$ & $14(13-15)$ \\
\hline \multirow[t]{3}{*}{ Caridina nilotica } & Aquarium & $35(33-37)$ & $33(31-35)$ \\
\hline & Channel & $36(35-38)$ & $35(34-37)$ \\
\hline & Combined & $35(34-37)$ & $34(33-36)$ \\
\hline
\end{tabular}

Where all $\mathrm{LC}_{50}(\mathrm{mS} / \mathrm{cm})$ are at $72 \mathrm{~h}$ except for $D$. carinata where $48 \mathrm{~h}$ results are used. These periods were chosen to minimise the difference between exposure periods between species.

\section{Effect of species selection}

There are clear differences in the mean salinity tolerances between the three studies using (artificial or natural) seawater and those using $\mathrm{NaCl}$ (Table 3). Assuming a similar difference in the toxicity of $\mathrm{NaCl}$ to Ocean Nature as observed in this study, $\mathrm{LC}_{50}$ values for $\mathrm{NaCl}$ were adjusted using Eq. (1) to give estimates of their value for Ocean Nature (Table 3). While this adjustment reduced the discrepancy between the studies, it did not eliminate it. The mean Ocean Nature adjusted $\mathrm{LC}_{50}$ from Blasius and Merritt (2002) and Palmer (unpublished) are about half that observed for Ocean Nature or sea-water by Kefford (2002), Kefford et al. (2003) and Shirgur and Kewalramani (1973) while about a third of that from

\begin{tabular}{|c|c|c|c|c|c|c|}
\hline \multicolumn{7}{|c|}{$\begin{array}{l}\text { TABLE2 } \\
\text { LC }_{50} \text { values in } \mathrm{mS} / \mathrm{cm} \text { (with } 95 \% \text { confidence interval) for the various salts tested. } \\
\text { ON = Ocean Nature. }\end{array}$} \\
\hline Species & Salt & $\begin{array}{l}\text { Control } \\
\text { mortality }\end{array}$ & $48 \mathrm{~h}$ & $72 \mathrm{~h}$ & $96 \mathrm{~h}$ & $240 h$ \\
\hline \multirow[t]{2}{*}{ Daphnia carinata } & ON & $0 \%$ & $11(10-12)$ & & & \\
\hline & $\mathrm{NaCl}$ & $0 \%$ & $4.5(3.8-5.0)$ & & & \\
\hline \multirow[t]{2}{*}{ Micronecta annae } & ON & $12 \%$ & & $13(11-16)$ & & \\
\hline & $\mathrm{NaCl}$ & $12 \%$ & & 11 (8.9-13) & & \\
\hline \multirow[t]{2}{*}{ Physa acuta } & $\mathrm{ON}$ & $0 \%$ & & $15(13-18)$ & $15(13-18)$ & \\
\hline & $\mathrm{NaCl}$ & $0 \%$ & & $8.7(7.6-9.9)$ & 8.7 (7.6-9.9) & \\
\hline \multirow[t]{3}{*}{ Caridina nilotica } & $\mathrm{ON}$ & $0 \%$ & & $36(34-41)$ & $35(33-40)$ & \\
\hline & $\mathrm{NaCl}$ & $0 \%$ & & $18(16-20)$ & $16(14-18)$ & \\
\hline & $\mathrm{Na}_{2} \mathrm{SO}_{4}$ & $0 \%$ & & $11(9.9-13)$ & $9.4(8.2-11)$ & \\
\hline \multirow[t]{2}{*}{ Euthraulus elegans } & $\mathrm{ON}$ & $23 \%{ }^{\#}$ & & $18(16-20)$ & $17(15-19)$ & $12(9.8-14)$ \\
\hline & $\mathrm{NaCl}$ & $23 \%{ }^{\#}$ & & $14(13-15)$ & $13(12-15)$ & $7.7(6.8-8.9)$ \\
\hline
\end{tabular}
Williams (1984). 


\section{Discussion}

\section{Effect of flow}

There was a remarkable similarity between the acute salinity tolerances of species tested in flowing and non-flowing environments, suggesting that, in most cases, flow has a minimal effect on the acute salinity tolerance of non-rheophilic macroinvertebrates. Given that tests in still water are much simpler, we recommend this environment be used for acute salinity tolerance testing of nonrheophilic macroinvertebrates. It remains to be shown whether the salinity tolerance of rheophilic macroinvertebrates is affected by flow.

\section{Effect of salt}

In contrast, four of five species had significantly higher $\mathrm{LC}_{50}$ values for Ocean Nature than for $\mathrm{NaCl}$. Although not statistically significant, the exception had the same trend. The differences between the salts were broadly constant across the different taxonomic groups and from species collected from Australia and South Africa. Subchronic exposure of $E$. elegans produced a similar difference in $\mathrm{LC}_{50}$ values between salts than did acute exposure. The constancy of this trend suggests that in most cases, acute tolerance to (artificial or natural) sea-water will probably be higher than $\mathrm{NaCl}$. Therefore direct comparison between tests using these salts is problematic. Despite differences in tolerances between the two salts, the $\mathrm{LC}_{50}$ for both salts was positively correlated and as measures of relative tolerance between species either should be useful. C. nilotica was also exposed to $\mathrm{Na}_{2} \mathrm{SO}_{4}$, which was more toxic than $\mathrm{NaCl}$ and this is in agreement with comparisons on other species (Goetsch and Palmer, 1997; Palmer and Scherman, 2000; Palmer, unpublished)

The presence of calcium and magnesium ions decreases the permeability and increases the integrity of cell membranes and their presence is known to reduce flows of both water and ions across the gills of fish (Rankin and Davenport, 1981: 66). Palmer and Scherman (2000) observed that calcium increased the salinity tolerance of Tricorythus tinctus (Ephmeroptera: Tricorythidae) while sulphate decreased its salinity tolerance. Likewise, Dwyer et al. (1992) observed that increased hardness (calcium and magnesium) increased the salinity tolerance of Daphnia magna and Morone saxatilis (striped bass). Calcium and magnesium in sea-water comprise about 18 and 3 meq \% of cations, respectively (Boulton and Brock, 1999), which might reduce sea-water's toxicity relative to that of $\mathrm{NaCl}$.

Mount et al. (1997) investigated the toxicity of 10 pure salts and their combined toxicity in (mass-based) one-to-one ratios. Their results for Daphnia magna and Ceriodaphnia dubia show that most combinations of two salts had lower $\mathrm{LC}_{50}$ values than one or both of the corresponding single salts. This trend was, however, less apparent in Pimephales promelas (fathead minnow). The presence of a single anion and a single cation, as in the case of exposure to $\mathrm{NaCl}$, may have a greater effect of an individual's ability to handle increased ionic concentrations compared with exposed to multiple cation and anions, as in the case of Ocean Nature.

Another possible reason for the difference in tolerance to Ocean Nature and $\mathrm{NaCl}$ may be $\mathrm{pH}$. High salinity treatments with Ocean Nature tended to have higher $\mathrm{pH}$ than the corresponding $\mathrm{NaCl}$ treatment (personal observations). In the $C$. nilotica experiment, for example, at $18 \mathrm{~g} / \ell$ of Ocean treatment the mean $\mathrm{pH}$ was 8.2, while $18 \mathrm{~g} / \ell$ of $\mathrm{NaCl}$ had a mean $\mathrm{pH}$ of 7.9. In freshwater fish and Daphnia magna, low $\mathrm{pH}$ inhibits sodium uptake and increases sodium loss (Aladin and Potts, 1995), although it is uncertain as to whether such

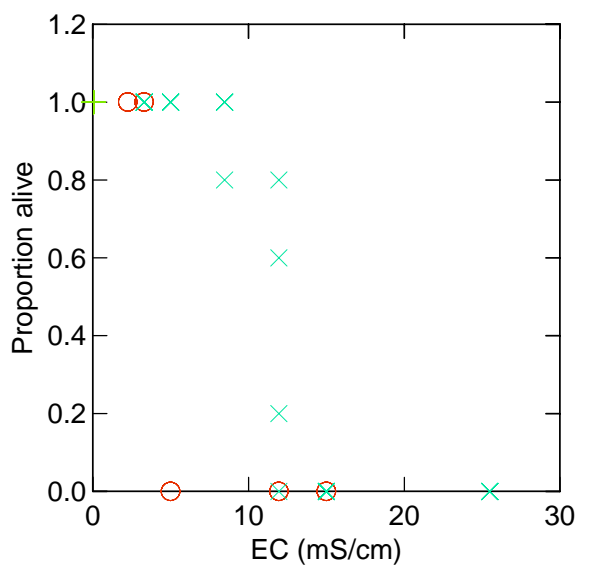

Salt

$\mathrm{NaCl}$

Ocean Nature

Control

Figure 2

Survival of Daphnia carinata over $48 h$ at different EC levels produced from Ocean Nature salt and $\mathrm{NaCl}$

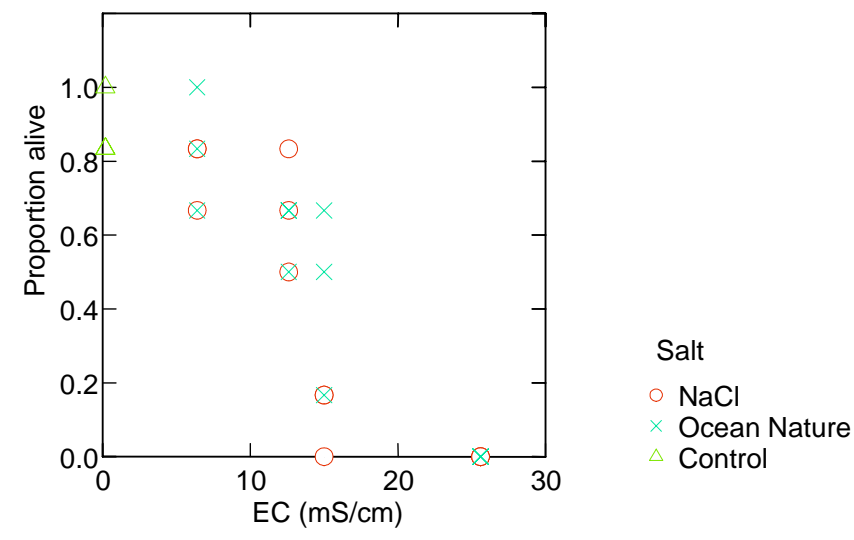

Figure 3

Survival of Microcronecta annae over $72 h$ at different EC levels produced from Ocean Nature salt and $\mathrm{NaCl}$

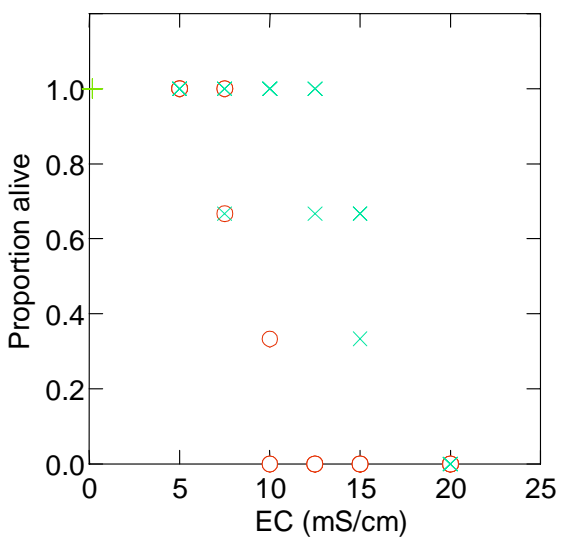

Salt

$\mathrm{NaCl}$

Ocean Nature

Control

Figure 4

Survival of Physa acuta over 72 and $96 \mathrm{~h}$ (there was no mortality between 72 and 96 h) at different EC levels produced from Ocean Nature salt and $\mathrm{NaCl}$ 
an effect would occur in the neutral to slightly alkaline waters of the current study.

In nature when salinity increases it will never be due to the addition of pure salts. As previously mentioned, in Australia, the increase in salinity will usually have ionic compositions close to that of sea-water. Experiments performed with $\mathrm{NaCl}$ in these circumstances will thus likely over-estimate the effects of salinity increases.

Inland waters are dominated by four major cations $\left(\mathrm{Ca}^{2+}, \mathrm{K}^{+}\right.$, $\mathrm{Mg}^{+}$and $\left.\mathrm{Na}^{+}\right)$and four major anions $\left(\mathrm{Cl}, \mathrm{SO}_{4}{ }^{2-}, \mathrm{HCO}_{3}{ }^{-}\right.$and $\left.\mathrm{CO}_{3}{ }^{2-}\right)$ (Kalff, 2002: 202) not to mention a large number of minor or trace elements. Even where rises in salinity tend to have ionic proportions similar to sea-water, minor variations in ionic proportions (Radke et al., 2002) may result in variation in the response of organism to salinity changes (see Radke et al., 2003). The acute toxicity of Ocean Nature to Daphnia carinata under-estimated the toxicity of three saline lake waters despite those waters having an ionic proportion similar to sea-water (Kefford, $2000 \mathrm{a}$; b). Toxicity testing of artificial water from one lake (water that was made up to have the identical ionic composition) suggested that the difference in toxicity could be accounted for by minor differences in the proportions of major ions (Kefford, 2000a), while in another lake, differences in the proportions of major ions only partly accounted for differences in toxicity. There is also the potential for increases of salinity to be accompanied by other changes in water quality (Kefford, 1998) and these changes may have effects on aquatic biota or may modify the effect that salinity has on aquatic biota.

Untangling the effects of different ionic concentrations on the salinity tolerance of a range of aquatic organisms would be a challenging task. Mount et al. (1997), for example, tested 1887 ion solutions using one species, Ceriodaphnia dubia, yet only considered combinations of salts in one to one ratios. Until a fuller understanding of the toxicity of differing ionic proportions on a range of species exists, compromises in selecting salt sources will be needed. Where studies are investigating the likely effects of general rises in salinity, a salt source with typical ionic proportions and exposure conditions is likely to be the most practical option. The potential for minor changes in ionic proportion (and other changes in water quality) to affect toxicity should be kept in mind. Where studies are investigating effects of salinity changes from specific sources, where practical, saline water from that source should be used.

An alternative approach would be to use $\mathrm{NaCl}$ as a 'worst case scenario'. If species are not affected by rises in salinity caused by $\mathrm{NaCl}$, then the current study suggests that they will not be affected if the ionic proportion is the same as sea-water. While this approach is conservative, it will result in species being over-protected. A balance will have to be struck between the costs and benefits from over- and under- protecting and the costs of determining their salinity tolerance.

\section{$72 \mathrm{~h}$ vs. $96 \mathrm{~h} \mathrm{LC}_{50}$}

As with Kefford (2002), the $\mathrm{LC}_{50}$ values calculated over both 72 and $96 \mathrm{~h}$ of exposure were similar, except for $M$. piccanina, which showed high mortality in all treatments between 72 and $96 \mathrm{~h}$ and its tolerance is therefore best considered over $72 \mathrm{~h}$. Acute toxicity tests with Daphnia species are usually conducted over $24 \mathrm{~h}$ or $48 \mathrm{~h}$ and $96 \mathrm{~h}$ is commonly used for fish (Walker et al., 1996: 127). Therefore conducting $72 \mathrm{~h}$ tests with most macroinvertebrates, which are between the size of Daphnia and fish, would seem reasonable.

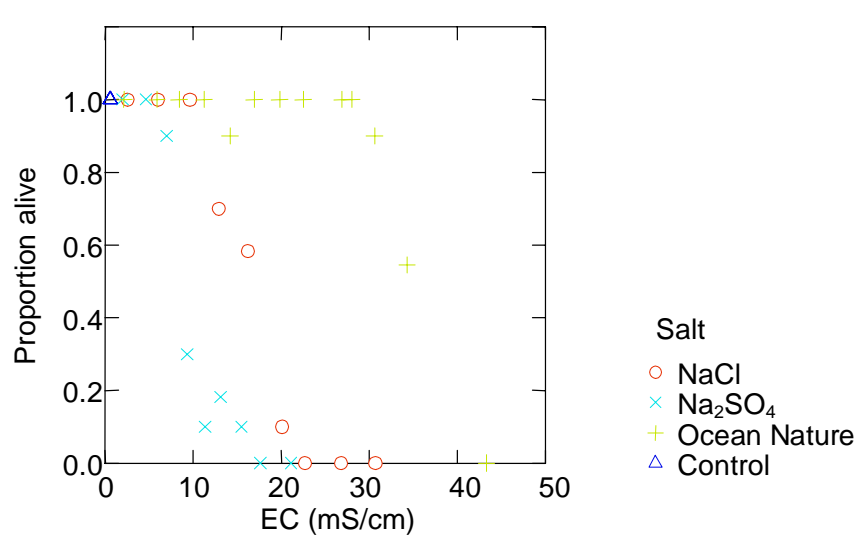

Figure 5

Survival of Caridina nilotica over $96 h$ at different EC levels produced from Ocean Nature salt, $\mathrm{NaCl}$ and $\mathrm{Na}_{2} \mathrm{SO}_{4}$

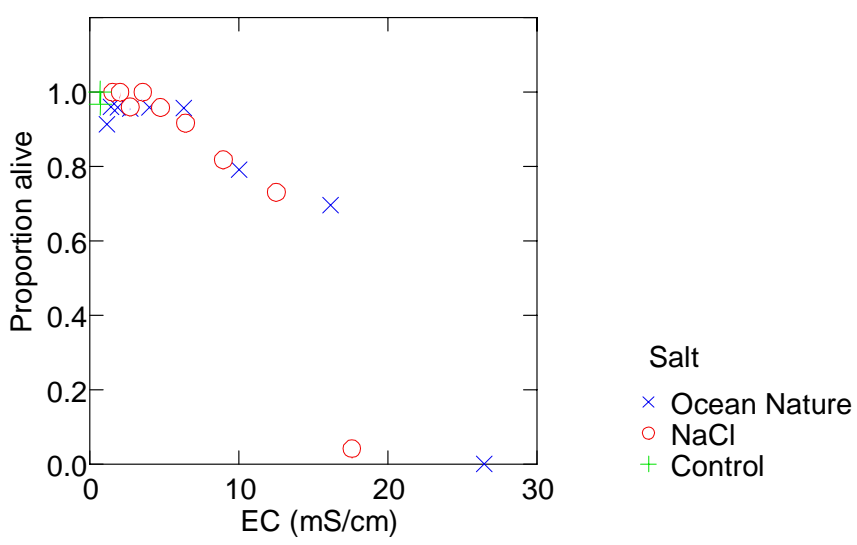

Figure 6

Survival of Euthraulus elegans over $96 h$ at different EC levels produced from Ocean Nature salt and $\mathrm{NaCl}$

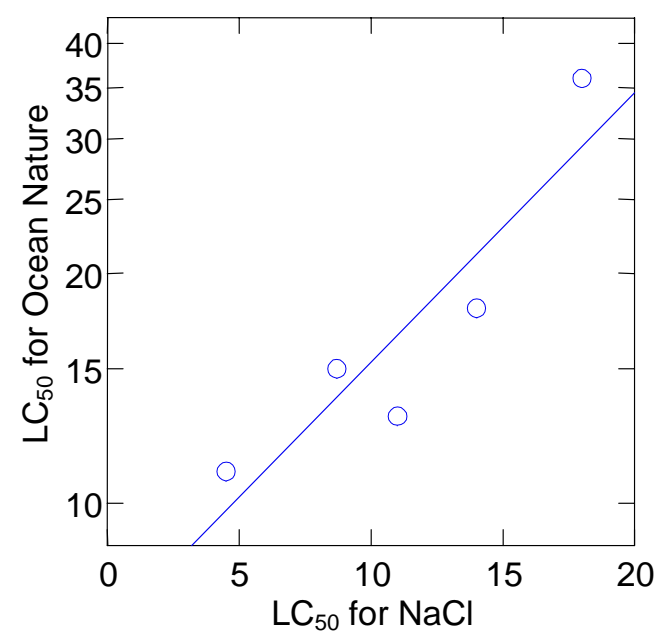

Figure 7

Relationship between $L C_{50}$ values for Ocean Nature salt and $\mathrm{NaCl}(\mathrm{mS} / \mathrm{cm})$. Values plotted are for $72 \mathrm{~h}$ except for D. carinata where $48 \mathrm{~h}$ results are plotted. The straight line is the least squares regression line. 


\section{Effect of species selection}

Various studies (Clemens and Jones, 1954; Shirgur and Kewalramani, 1973; Williams, 1984; Blasius and Merritt, 2002; Palmer, unpublished; Kefford, 2002; Kefford et al., 2003) indicate considerable differences in salinity tolerance, which do not appear to be wholly explainable due to the use of $\mathrm{NaCl}$ or (artificial or natural) sea-water. Macroinvertebrate taxa found in low local abundances (or rare) tend to have a higher $\mathrm{LC}_{50}$ than common taxa (Kefford, 2002; Kefford, et al 2003). The mean $\mathrm{LC}_{50}$ for common macroinvertebrates from Kefford (2002) and Kefford et al. (2003) were 17 and $21 \mathrm{mS} / \mathrm{cm}$, respectively. These values are closer to the mean Ocean Nature adjusted $\mathrm{LC}_{50}$ value of $14 \mathrm{mS} / \mathrm{cm}$ from both Palmer (unpublished) and Blasium and Merritt (2002) who tested only common species. Two possible reasons for the remaining discrepancy between studies include:

- Real differences in the salinity tolerances of macroinvertebrates from different locations

- In testing relatively few species, only those with a limited tolerance range were selected (see Forbes and Calow 2002).

In particular, Palmer (unpublished) and Williams (1984) selected mostly Ephmeroptera and macrocrustaceans, respectively, for testing; members of the former tend to be salt-sensitive and the latter tend to be salt-tolerant (Kefford et al., 2003). It is therefore possible that differences between studies may be partly caused by the use of different salts and from the taxa chosen for testing.

Criteria by which taxa are included in studies of salinity tolerance are of critical importance. Studies determining the salt sensitivity of specific taxa at a location will probably not reflect the salinity tolerance of the range of taxa present at that location unless a large number of species are chosen from a range of taxonomic groups and rarities. Comparing results from such studies to those that consider a small number of common species or species from restricted taxonomic groups may result in large differences between the studies. Thus apparent differences in salinity tolerances between studies conducted at different locations may not reflect real differences in the tolerances of macroinvertebrates.

\section{Acknowledgements}

A Land and Water Australia (LWA) Travelling Fellowship (project RMI 11), an RMIT travel grant and running costs and in-kind contributions from UCEW-IWR made BJK's trip to South Africa possible. LWA through the National Dryland Salinity Program (project VCE 17) funded the Australian component and BJK completed this work while in the receipt of an RMIT Ph.D. scholarship. We are grateful for this financial support. We thank Elizabeth Fields, Rupert Jackson, Tony Palmer, Jacqueline Salter and Ntomboxolo Valisa for assistance in the laboratory and/or the field, Natalie Burfurd and Liliana Zalizniak for proof-reading and Richard Marchant for comments on the manuscript and lively discussion. Any errors or omissions are, however, our own.
TABLE 3

Summary of $L_{50}$ values from various studies: mean value (and range) $\mathrm{N}=\mathrm{NaCl}$ adjusted to Ocean Nature from Equation 1.

\begin{tabular}{l|c|c|c} 
Salt source & $\mathbf{7 2} \mathbf{h}$ & $\mathbf{9 6} \mathbf{h}$ & Source \\
& & nd & 1 \\
ON & $31(5.5-76) n=57$ & $43(31-61) n=6$ & 2 \\
Sea-water & nd & $31(8.5-47) n=41$ & 3 \\
ON & $32(11-47) n=43$ & $8.6(6.7-11) n=6$ & 4 \\
$\mathrm{NaCl}$ & nd & $14(12-17) \mathrm{n}=6$ & 4 \\
$\mathrm{Ad} . \mathrm{ON}$ & nd & $6.6(3.9-11) \mathrm{n}=4$ & 4 \\
$\mathrm{Na} \mathrm{SO}_{4}$ & nd & $8.4(4.7->13) \mathrm{n}=6$ & 5 \\
$\mathrm{NaCl}$ & nd & $14(9.8->15) \mathrm{n}=6$ & 5 \\
$\mathrm{Ad} . \mathrm{ON}$ & nd & $14(5.6-23) \mathrm{n}=4$ & 6 \\
$\mathrm{NaCl}$ & nd & $26(11-43) \mathrm{n}=4$ & 6 \\
$\mathrm{Ad} . \mathrm{ON}$ & nd & & 7 \\
Sea-water & $29(19-46) \mathrm{n}=12 \#$ & &
\end{tabular}

1 = Kefford et al. (2003), 2 = Williams (1984), 3 = Kefford (2002), 4 = Palmer

\# Estimated over approximately $72 \mathrm{~h}$ from data given in the original paper, which report survival time at various salinity.

\section{References}

AGRESTI A (1990) Categorical Data Analysis. John Wiley \& Sons, Inc, New York. 558 pp.

ALADIN NV and POTTS WTW (1995) Osmoregulatory capacity of the Cladocera. J. Comp. Phys. B 164 671-683.

ASTM (1998) Annual book of ASTM Standards, Water and Environmental Technology, Biological Effects and Environmental Fate, Biotechnology; Pesticides. Volume 11.05. American Society for Testing and Materials, West Coshohocken.

BAYLY IAE and WILLIAMS WD (1973) Inland Waters And Their Ecology. Longman Australia Pty Limited, Hawthorn, Australia. $316 \mathrm{pp}$.

BLASIUS BJ and MERRITT RM (2002) Field and laboratory investigations on the effects of road salt $(\mathrm{NaCl})$ on stream macroinvertebrate communities. Environ. Pollut. 120 219-231.

BOULTON AJ and BROCK MA (1999) Australian Freshwater Ecology Processes and Management. Gleneagles Publishing, Glen Osmond, Australia. 299 pp.

CLEMENS HP and JONES WH (1954) Toxicity of brine water from oil wells. Trans. Am. Fish. Soc. 84 97-109.

CLUNIE R, RYAN T, JAMES K and CANT B (2002) Implications for Rivers from Salinity Hazards: Scoping Study. Report produced for Murray-Darling Basin Commission, Strategic Investigations and Riverine Program - Project R2003. Department of Natural Resources and Environment, Heidelberg, Australia.

DALLAS HF and DAY JA (1993) The Effect of Water Quality Variables on Riverine Ecosystems: A Review. Water Research Commission Report No TT 61/93, Pretoria, South Africa.

DWAF (2000) A Protocol for Acute Toxicity Testing Using Selected Riverine Invertebrates in Artificial Stream Systems. Version 1.0. Department of Water Affairs and Forestry, Pretoria, South Africa.

DWYER FJ, BURCH SA, INGERSOLL CG and HUNN JB (1992) Toxicity of trace element and salinity mixtures to striped bass (Morone saxatilis) and Daphnia magna. Environ. Toxicol. Chem. 11 513-520.

FORBES VE and CALOW P (2002) Species sensitivity distributions revisited: A critical appraisal. Human and Ecological Risk Assessment 8 473-492. 
GOETSCH PA and PALMER CG (1997) Salinity tolerance of selected macroinvertebrates of the Sabie River, Kruger National Park, South Africa. Arch. Environ. Cont. Toxicol. 32 32-41.

HART B, BAILEY P, EDWARDS P, HORTLE K, JAMES K, McMAHON A, MEREDITH C and SWADLING K (1991) A review of salt sensitivity of Australian freshwater biota. Hydrobiol. 210 105-144.

HERCZEG AL, DOGRAMACI SS and LEANEY FWJ (2001) Origin of dissolved salts in a large, semi-arid groundwater system: Murray Basin, Australia. Mar. Freshwater Res. 52 41-52.

KALFF J (2002) Limnology: Inland Water Ecosystems. Prentice Hall: Upper Saddle River, New Jersey. 592 pp.

KAY WR, HALSE SA, SCANLON MD and SMITH WJ (2001) Distribution and environmental tolerances of aquatic macroinvertebrate families in the agricultural zone of southwestern Australia. J. North Am. Benth. Soc. 20 182-199.

KEFFORD BJ (1998) Is salinity the only water quality parameter affected when saline water is disposed in rivers? Int. J. of Salt Lake Res. 7 285-300.

KEFFORD BJ (2000a) A preliminary investigation of the toxicity of saline lakes that are disposed into the Barwon River, south-west Victoria. Department of Natural Resources and Environment. Heidelberg, Australia.

KEFFORD BJ (2000b) The effect of saline water disposal: implications for monitoring programs and management. Environ. Monit. Assess. 63 313-327.

KEFFORD BJ (2002) South African study tour: effects of salinity on aquatic invertebrates. Final Report for Ben J. Kefford's Travelling Fellowship (Land and Water Australia project no RMI 11). Department of Biotechnology and Environmental Biology, RMIT University, Bundoora, Australia.

KEFFORD BJ, DALTON A, PALMER CG and NUGEGODA D (2004) The salinity tolerance of eggs and hatchlings of selected aquatic macroinvertebrates in south-east Australia and South Africa. Hydrobiol. 517 179-192.

KEFFORD BJ, PAPAS PJ, CROWTHER D and NUGEGODA D (2002) Are salts toxicants? Australas. J. Ecotoxicol. 8 63-68.

KEFFORD BJ, PAPAS PJ and NUGEGODA D (2003) Relative salinity tolerance of macroinvertebrates from the Barwon River, Victoria, Australia. Mar. Freshwater Res. 54 7555-765.

MILLS BJ, and GEDDES MC (1980) Salinity tolerance and osmoregulation of the Australian Freshwater Crayfish Cherax destructor Clark (Decapoda: Parastacidae). Aust. J. Mar. Freshwater Res. 31 667-676.

MOUNT DR, GULLEY DD, HOCKETT JR, GARRISON TD, and EVANS JM (1997) Statistical models to predict the toxicity of major ions to Ceriodaphnia dubia, Daphnia magna and Pimephales promelas (flathead minnows). Environ. Toxicol. Chem. 16 20092019.

NIELSEN DL and HILLMAN TJ (2000) Ecological Effects of Dryland Salinity on Aquatic Ecosystems. Technical Report 4/2000, Cooperative Research Centre for freshwater Ecology. Albury, Australia.

OECD (1996) Guidelines for Testing of Chemicals. Organization for Economic Cooperation and Development. Paris.

PALMER CG (unpublished) UCEW-IWR unpublished database. Grahamstown, South Africa.
PALMER CG (1999) Application of ecological research to the development of a new South African water law. J. North Am. Benth. Soc. 18 132-142.

PALMER CG, GOETSCH PA, and O’KEEFFE JH (1996) Development of A Recirculating Artificial Stream System to Investigate the Use of Macroinvertebrates as Water Quality Indicators. Water Research Commission Report No 475/1/96, Pretoria, South Africa.

PALMER CG and ROSSOUW N (2000) Olifants River Ecological Water Requirements Assessment. Report no PB000-00-5999, Department of Water Affairs and Forestry, Directorate Project Planning, Pretoria, South Africa.

PALMER CG and SCHERMAN P-A (2000) Application of an Artificial Stream System to Investigate the Water Quality Tolerances of Indigenous, South African, Riverine Macroinvertebrates. Water Research Commission Report No 686/1/00, Pretoria, South Africa.

RADKE LC, HOWARD KWF and GELL PA (2002) Chemical diversity in south-eastern Australian saline lakes I: Geochemical causes. Mar. Freshwater Res. 53 941-959.

RADKE LC, JUGGINS S, HALSE SA, DE DECKER P and FINSTON $\mathrm{T}$ (2003) Chemical diversity in south-eastern Australian saline lakes II: Biotic implications. Mar. Freshwater Res. 54 895-912.

RANKIN JC and DAVENPORT JA (1981) Animal Osmoregulation. Blackie \& Sons Limited, Glasgow, UK. 202 pp.

SHIRGUR GA and KEWAIRAMANI HG (1973) Observations of salinity and temperature tolerance of some of the freshwater insects. J. Biol. Sci. 16 42-52.

SHORT TM, BLACK JA and BIRGE WJ (1991) Ecology of a saline stream: community responses to spatial gradients of environmental conditions. Hydrobiol. 226 167-178.

SMITH PJ (2002) Analysis of Failure and Survival Data. Chapman \& Hall/CRC, Boca Raton. 254 pp.

WALKER CH, HOPKIN SP, SIBLY RM and PEAKALL DB (1996) Principles of Ecotoxicology. Taylor \& Francis, London. 256 pp.

WILLIAMS DD and WILLIAMS NE (1998) Aquatic insects in an estuarine environment: Densities, distribution and salinity tolerance. Freshwater Biol. 39 411-421

WILLIAMS DD, WILLIAMS NE and CAO Y (1999) Road salt contamination of groundwater in a major metropolitan area and development of a biological index to monitor its impact. Water Res. 34 127-138.

WILLIAMS WD (1984) Salinity as a Water Quality Criterion and Determinant in Australia. Australian Water Research Council, Research Report No. 80/121, Canberra, Australia.

WILLIAMS WD (1987) Salinization of rivers and streams: an important environmental hazard. Ambio 16 180-185.

WILLIAMS WD and BUCKNEY RT (1976a) Stability of ionic proportions in five salt lakes in Victoria, Australia. Aust. J. Mar. Freshwater Res. 27 367-377.

WILLIAMS WD and BUCKNEY RT (1976b) Chemical composition of some inland surface waters in South, Western and Northern Australia. Aust. J. Mar. Freshwater Res. 27 379-397. 